\title{
XXVII.
}

\section{Ueber die Veränderungen, welcle unter dem Einflusse des Silbers im Blute und im Bau der Gewebe erzeugt werden.}

Von Dr. Bogoslowsky aus Moskau.

Die ersten Versuche einer wissenschaftlichen Bearbeitung der Frage von der Wirkung des Silbers auf den thierischen Organismus beginnen erst mit den Arbeiten Orfila's (Lehrbuch der Toxicologie, nach der fünten umgearbeiteten Auflage von Dr. Krupp, 1854), Orfila hat dabei aus einer Reihe von Versuchen, die er in dem Abschnitle „die Wirkung des salpetersauren Silbers auf den thierischen Organismus" anführt, keine positiven Schlüsse gezogen. Seine sämmtlichen Versuche (sieben an der Zahl) wurden von ihm an Hunden angestellt, denen er salpetersaures Silber entweder in den Magen oder unmittelbar in den Blutstrom einführte und zwar durch Einspritzung verschiedener Dosen in die Jugular-Vene, obne die eine Thrombose der Gefässe durch Pfropfen bedingende coagulirende Wirkung des Silbers auf das Blut hierbei zn berícksichtigen. Die je nach der Grösse der Dosell früher oder später auftretenden Anfälle erschwerten Athmens, die von ihm in den Lungen, bei der Obduction vorgefundenen verhärteten, nicht knisternden, Iuftleeren Stellen, die dunkle Färbung des Blutes in den Arterien bestätigen das oben Gesagte. Einigermaassen grösseres Interesse bietet die chemische Seite der Arbeit. Nachdem er nehmlich mittelst der Oesophagotomie und Unterbindung des Oesophagus verschiedene Quantitäten salpetersauren Silbers in den Magen eines Hundes eingebracht hatte, fand er dasselbe jedesmal nach Verlauf von einigen Stunden in der Leber und der Milz abgelagert vor. In dem siebenten Versuche, bei welchem in den Magen eines Hundes $1 \frac{1}{2}$ Drachmen eingeführt und dabei die Speiseröhre und der Penis unterbunden wurden, trat der Tod nach 20 Stunden von Beginn des Versuches ein; die Analyse des Urins wies in demselben die Anwesenheit des Silbers nach. Was aber die Ausscheidung des Silbers 
durch den Urin bei Fülterung des Jundes mit diesem Mittel in sehr kleinen Dosen betrifft, so hat 0rtila dasselbe nie im Harn entdeckt, obwohl der Versuch einige Monbate hindurch dauerte und man bei dieser Gelegenheit stets in der Leber und der Milz Silber nachweisen konnte.

Seit Orfila's Werk ist bis 1845 in Betreff dieses Metalls keine bedeutende Arbeit erschienen, ausser derjenigen Krahmer's in diesem Jahre, welche grosse Aufmerksamkeit auf sich gelenkt hat. Seine Broschüre: „Das Silber, als Arzneimittel betrachtet, " enthält ausser den bis dahin bekannten, die Wirkung des Silbers betreffenden Thatsachen eine selbständige Untersuchung über das Verhalten des salpetersauren Silbers zum gesunden Organismus. Die Versuche, die Verfasser mit sich selbst unternommen hat, halten indess keine Kritik aus. Die von ihm in Betreff des Einflusses des salpetersauren Silbers auf die im Organismus vorgehende Metamorphose gezogenen Schliusse sind mindestens sehr zweifelhaft. Eine schlecht gewählte Diät, die auf seine Ernährung störend eingewirkt und welche noch vor dem Gebrauch des Silbers hartnäckige Verstopfung zu Stande gebracht hat, hinderten ihn, wie er selbst bekannte, von der Richtigkeit der erhaltenen Resultate uiberzeugt zu sein. Es war schwer, zu sagen, wovon die von inm beobachteten Veränderungen des Organismus eigentlich abhingen, ob man dieselben als eine Folge des Einflusses der ungewohnten Diät oder des von ihm gebrauchten Mittels zu betrachten hatte.

Ueber die in den anderweitigen Organen durch den Gebrauch des Silbers hervorgerufenen Veränderungen, über die functionellen Störungen, die unter dem Einflusse des Silbers im Organismus entstehen, finden wir in der Arbeit von Krahmer keine Untersuchungen ror.

Im Laufe des Jahres 1864 wurde, auf Gharcot's Veranlassung von Ball (Des phénomênes toxiques, déterminés par infection des sels d'argent dans le torrent circulatoire. Gazette Médic. 1864) physiologische Beobachtungen über die Wirkung des Silbers angestellt. Die Ergebnisse seiner Einspritzungen in das Blut sind von den von Krahmer und Orfila angeführten Resultaten, auf welche sich einzig und allein die bisherige therapeutische Anwendung und die Meinungen über die Wirkung des Silbers stüzten, wesentlich verschieden. Der Zweck der von ihm unternommenen Arbeit war: 
die Wirkung der Silbersalze bei unmittelbarer Mischung derselben mit dem Blute, abgesehen von deren coagulirendem Einfluss auf das letztere, aufzuklären. Zu diesem Ende bediente er sich einer Auflösung eines Silberalbuminats und späterhin wandte er phosphorsaures und doppelt Silber-Natron-Salz an. Ausser den ErstickungsErscheinungen beobachtete der Autor noch eine Paralyse des hinteren Theiles des Rumpfes, welche durch die plötzliche Erschlaffung der hinteren Extremitäten sich kund gab. Sich auf diese Beobachtungen stützend, glaubt er daher, dass der Tod hei einer SilberVergiftung nicht ausschliesslich als eine Folge der durch die däbei statthabende copiöse Ausscheidung von Schleim. in den Lungen verursachten Erstickung, sondern auch noch der besonderen toxischen Wirkung des Mittels selbst auf das Nervensystem, betrachtet werden müsse, ferner, dass die copiöse Ausscheidung des Schleimes aus den Lungen ebenfalls nur nervöser Abkunft und auf dem Wege des Reflexes bewerkstelligt sei, da die chemische Analyse der Secrete das Vorhandensein des Silbers in denselben nicht nachweisen konnte. Dies sind die Resultate seiner toxicologischen Arbeit. Eine fernere Bearbeitung dieser Frage ist noch bis jetzt vom Verfasser nicht veröffentlicht worden.

Im Jahre 1866 wurden die Beobachtungen von Schumowsky und Ball in Betreff der Wirkung der Silberalbuminate von Professor Sokolowsky in Moskau einer genaueren Prüfung unterworfen und letzterer kam dabei zu folgenden Resultaten, die er in seinem Werke: "Der Versuch einer Theorie der Pharmocologie nebst einer pharmocologischen Technik" veröffentlicht hat. Die Blutkörperchen waren ausserordentlich verkleinert, blass in Folge der Auflösung des Hämaglobins. Nach Einspritzung von Albuminaten in die Vene eines Hundes faud er beständig Eiweiss im Urin, wobei das Blut der vergifteten Thiere ein theeriges Aussehen erhalten und seine Fähigkeit zu gerinnen eingebüsst hatte. Das Herz eines Frosehes in eine Albuminat-Auflösung getaucht, blieb plötzlich still : stehen, jedoch stellten sich auf Reizung wieder Contractionen ein, die allmählich schwächer wurden und endlich in locales, fibrilläres Zittern über-

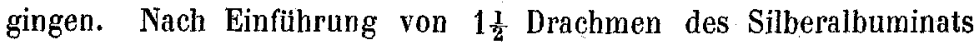
in das Blut wurde der Herzschlag langsamer, das Athmen erschwert und das Zwerchfell blieb endlich in der Inspirationsstellung unter Spannung der Bauchdecken stehen. Nach dem Aufhören der Ath- 
mung wurde der Herzschlag, wenn auch schwach, doch noch bemerkbar.

Damit sind sämmtliche in den früheren Arbeiten auf dem Wege des Experiments erzielten Thatsachen in Betreff des Silbers erschöpft. Dieselben gestatten durchaus noch keinen klaren Begriff von dem Verhalten der Silberpräparate zu den verschiedenen Systemen des Organismus und noch weniger ist hier die Möglichkeit gegeben, anf Grund dieser Ergebnisse eine rationelle Anwendung des Silbers in der Therapie aufustellen. Die einen der angeführten experimentellen Arbeiten liefern entweder gar keine Resultate ( 0 rfila) oder waren der Art, Jass bei deren Ausführung den unumgänglichen Bedingungen, von denen die Richtigkeit der Resultate abhing, nicht Rechnung getragen wurde. So z. B. wurde in den Arbeiten von Krahmer und Orfila die coagulirende Wirkung des salpetersauren Silbers auf das Blut ausser Acht gelassen, während dieses Salz dem Blute unmittelbar zugeführt, Trombose der Gefässe, keineswegs aber Symptome der toxischen Einwirkung des Silbers herbeigeführt hat. Die anderen über dieses Thema erschienenen Arbeiten, bèi denen zwar zu den Versuchen Verbindungen von Silber angewandt worden sind, die auf das Eiweiss des Blutes keine coagulirende Wirkung zur Geltung brachten, sind indess nicht vollständig und höchst einseitig, und handeln nur entweder von den allgemeinen Symptomen bei der Wirkung, dieses Mittels (Ball), oder von dem Einflusse dieses letzteren auf das Blut etc. (Sokolowsky). Allein nach einer vollständigen Aufklärung des Verhältnisses der Silberpräparate zu den sämmtlichen Systemen des Districts; wo sich die Hauptwirkung des Silbers concentrirt - und überhaupt - der in Folge eines anhaltenden Gebrauches dieses Mittels zu Stande kommenden anatomischpathologischen Vẹänderungen, habe ich in diesen Arbeiten vergebens geforscht.

Es schien mir nun werth, für dieses Mittel, welches in neuerer Zeit eine so ausgedehnte therapeutische Anwendung gefunden, aus diesem Grunde und wegen der oben erwähnten Mängel in seiner Erforschung eine specielle Untersuchung anzustellen. Die Resultate derselben sind übrigens schon in russischer Sprache veröffentlicht worden.

In der gegenwärtigen Abhandlung beabsichtige ich, einen Theil meiner bereits vollendeten Arbeit in Betreff des Einflusses des Sil- 
bers auf das Blut und den Bau der Gewebe darzustellen, Ich halte mich dabei verpflichtet, dem Herm Professor A. A. Sokolowsky, in dessen pharmacologischen Institute ich meine Arbeiten zis Stande gebracht, und dem Prosector der pathologischen Anatomie an der Moskauer Universität, Herrn J. Th. Klein, hiermit meinen aulrichtigsten Dank für deren grosses Interesse an meiner Arbeit auszusprèchen.

Eine der bedeutenden Schwierigkeiten, auf welche man bei der Untersuchung der Wirkung der Silbersalze schon von vorn herein stiess, war unstreitig die Wahl einer zu diesem Zwecke geeigneten Form. Fast sämmtliche Silbersalze, direct in das Blut oder subcutan in der Form einer wässrigen Lösung eingespritzt, bringen Gerinnung des ersteren hervor; schon dadurch allein kommt in dem einen Falle eine Verstopfung der Capillaren zu Stande, in dem zweiten bleiben sie unresorbirt und rufen in Folge dessen keine allgemeinen Symptome hervor; - in den Magen eingeführt treten sie nur ungleichmässig und unsicher, je nach der Verschicdenheit der dargereichten Dosen, in den Organismus über. Besonders ist das salpetersaure Silber mit diesen für die Untersuchung so unginstigen Eigenschaften ausgestattet. Wir sahen uns also in der Nothwendigkeit, bei unseren Versuchen mit diesem Salze dassclbe in eine Form zu bringen, in welcher es vor Allem auf das Eiweiss nicht mehr gerinnend einwirkte. Zu diesem Ende fanden wir es am Geeignetsten, uns des Gebrauchs der bisher zu pharmacologischen. Untersuchungen von Metallen unseres. Wissens noch von Niemandem in Anwendung gebrachten Peptonlösungen des Silbers zu bedienen.

Zur Herstellung der letzteren eignet sich am besten - der Magen eines jungen Kaninchers. Zwei Stunden nach der Fütterung tödteten wir es durch einen Stich in die Medulla oblangata und nahmen sofort den Magen heraus. Zuerst wurde derselbe rein gewaschen, dann seine Schleimbaut mittelst eines Scalpels abgeschabt und mit Sand in einein Mörser zusammen gerieben. Die auf diese Weise geriebene Schleimhaut liessen wir 24 Stunden lang in destillirtem Wasser, welches auf $1000 \mathrm{Ccm}$. $\frac{1}{2} \mathrm{Ccm}$. Chlorwasserstoffsäure enthielt, aufweichen. Die Flüssigkeit wurde dann abgegossen und darin frisch aus dem̄ Blute eines Kalbes ausgewaschenes Fibrin einige Stunden lang in einem Wasserbade, bei einer Temperatur 
von $38^{\circ} \mathrm{C}$., zur Verdauung gebracht. In den meisten Fällen verdaute 1 Unze des gut bereiteten Magensaftes 1 Drachme Fibrins und 1 Drachme des so erbaltenen Peptons löste leicht und ohne die geringste Trübung zu bewirken, bis 2 Gran salpetersaures Silber auf. Das fernere Zuthun dieses Salzes liess bei fallendem Lichte die Flüssigkeit etwas opalfarbig erscheinen, ohne jedoch einen Niederschlag zu setzen. Unter die Haut eines Frosches gespritzt, wurde diese Lösung resorbirt, okne Verbrennung zu verursachen, und rief so ein voliständiges und klares Bild derselben Wirkung hervor, wie beim Hunde nach Einsprifzung dieser Lösung in die Vene; dem frisch gelassenen arteriellen Blute beigemischt, hebt dieselbe die Gerinnungsfähigkeit des letzteren auf, obne dabei Coagula zu bilden.

Eben dieselben Eigenschaften besitzt noch ein zweites SilberPräparat, nehmlich das bereits von Benj. Ball in seinen Versuchen in Anwendung gebrachte doppelte Silber-Natronsalz, dessen Formel 2 $\left(\mathrm{NaO}, \mathrm{S}_{2} \mathrm{O}_{2}\right)+\mathrm{AgO}, \mathrm{S}_{2} \mathrm{O}_{2}+2 \mathrm{HO}$ ist und dessen Zubereitung man z. B. bei Graham (Lehrbuch der Chemie, Braunschweig 1863) dargestellt finden kann. Dieses Salz bewirkt, wie schon oben bemerkt, keine Gerinnung des Eiweisses, wird durch Chlorwasserstoffsäure nicht präcipitirt, hingegen leicht resorbirt und wirkt als Silber, da das in ihm enthaltene schwefligsaure Natron (Natrum hyposulphorosum) sich in verhältnissmässig grösseren Dosen zu dem Organismus indifferent zu verhalten pflegt. In Folge der beschriebenen Eigensebaften dieser beiden letzten Präparate haben wir dieselben bei unseren Versuchen, die wir über die specielle Wirkung des Silbers angestellt haben, in Anwendung gebracht und dabei stets Sorge getragen, beide möglichst Hạnd in Hand in die Versuche zu führen. Jedoch baben wir ausser diesen beiden Salzen noch Silberalbuminate gebraucht. Wir fütterten mit denselben Kaninchen, um hernach die in Folge des nachhaltigen Gebrauches des Silbers in den inneren Organen des Thieres vorgehenden Veränderungen studiren zu können.

Die hier von uns vorzuführenden Beobacbtungen handeln hauptsächlich von der mikroskopischen und chemischen Analyse des Blutes und den in Folge des Gebrauches von Silber entstehenden und mit den den materiellen Hauptgrund der Einwirkung dieses Mittels auf den Organismus ausmachenden Veränderungen im Blute, eng verbundenen Veränderungen in dem Baue der Gewebe. Zu 
diesem Ende wurde einem Hunde mittlerer Grösse 0,1 Gramm salpetersauren Silbers in einer Pepton-Auflösung eingeführt, bald nach dem Tode des Thieres das Blut aus dem rechten Herzen genommen und zum Vergleiche das Blut aus der Vene eines gesunden Hundes gelassen. Die miltelst der feuchten Camera unternommene vergleichende mikroskopische Untersuchung des Blutes ans dem vergifteten und dem nicht vergifteten Thiere ergaben Folgendes: Die rothen Blutkörperchen aus dem vergifteten Blute erschienen bedeutend blasser und deren Contouren zarter als gewöhnlich; die weissen Blutkörperchen hingegen erlitten keine Veränderung. Die Intercellular-Substanz, anfangs durchsichtig, wurde bald (nach $10 \mathrm{Mi}-$ nuten) von einer feinkörnigen Masse des geronnenen Fibrins besäet. Die sofort vorgenommene Untersuchung des Blutes mittelst eines Spektroskops zeigte im Spectrum keine Abweichungen. Die characteristischen beiden dunklen Streifen in dem Hämoglobinspectrum traten deutlich im Gesichtsfelde hervor.

Aehnliche mikroskopisehe Veränderungen fanden wir nach Verlauf einiger Zeit auch in dem Blute eines mittelst eines doppelten Silbersalzes vergifteten Thieres; jedoch zèigten die Blutkörperchen dieses Blutes ein noch auffallenderes Hellwerden des Protoplasma und hatten dieses Mal verhältnissmässig feinere Contourirung der Ränder, welche nur bei einer gewissen Focusweite deutlich wahrgenommen werden konnte. Die Intercellularsubstanz bestand ebenfalls aus einer feinkörnigen Masse geronnenen Fibrins. Die wiederum vorgenommene Untersuchung mittelst eines Spectral-Apparates entdeckte ebenfalls keine Veränderung in dem normalen Spectrum des Blutes; nur bemerkten wir in dem gegenwärtigen Falle im gelben Lichte des Blufspectrums bei einem gewissen Grade der Verdichtung der Flüssigkeit, bei welchem die zwei charakteristischen Hämoglobin-Streifen noch nicht zum Vorschein kamen, einen schmalen schwarzen, nach den Seiten hin dem einen oder dem anderen Dichtigkeitsgrade der Lösung entsprechend ausgebreiteten Streifen, welcher das Hämatin-Spectrum characterisirte.

Das Blut aus einem mittelst einer Peptonatlösung vergifteten Thiere lieferte nach Verlauf einiger Stunden nach dem Versuche ebenfalls einen ziemlich deutlichen characteristischen Hämatin-Streifen, welcher bei einem gewissen Grade von Dichtigkeit zum Vorschein kam; das zur Vergleichung stehen gelassene normale Blut 
ergab nichts Aehnliches. Zur V'ervollständigung der eben constatirten Veränderungen wurde von uns durch Beimischung der verschiedenen Silbersalzlösungen zu einem Tropfen herausgelassenen Blutes, noch eine Anzahl von Beobachtungen uber die unmittelbare Wirkung der Silbersalze auf das Blut eines Thieres ausserhalb des Organismus angestellt. Die in Betreff der Veränderungen der Blutkörperchen angestellten Beobachtunger wurden, wie vorber, mit Hilfe einer feuchten Camera bewerkstelligt.

Ausserdem werden wir hier die Resultate der von uns bei solchen Mischungen ausgeführten Spectral-Analyse auseinandersetzen.

\section{1) Der Einfluss einer Lösung des salpetersauren Silbers auf die Blutkörperchen.}

Giesst man vorsichtig einen Tropfen von einer concentrirten Lösung des salpetersauren Silbers zu einem unter das Mikroskop gebrachten Tropfen Blutes, so beginnen die auf der Berührungsstelle mit dem Salze befindlichen Blutkörperchen ihre Gestalt zu verändern, indem sie eine deutliche Abzeichnung doppelter Contouren erhalten, so dass sie an Knorpelzellen erinnern. Dabei bleibt der äussere Formabriss der Blutkörperchen unverändert, allein uach einiger Zeit (gewöhnlich nach 5-10 Minuten nach Zuführung des Mittels) geht diese Form in eine elliptische, runde oder eckige, über. Die Zellenkerne (wenn wir es mit dem Blute eines Frosches zu thun baben) erhielten eine gelbliche Sebattirung und zeichneten sich deutlich von dem blass gewordenen Protoplasma ab. Bei der ferneren Einwirkung des Mittels (gewöhnlich nach Verlauf yon 20 bis 30 Minuten) nahm die doppelte Contour der Zellen ebenfalls eine gelbliche Schattirung an, während das mehr im Innern befindliche protoplasma fast völlig entfärbł erschien. Nach einiger Zeit bildete sich in den Zellenkernen eine feinkörnige Masse, welche vorziiglich im Centrum des Kernes beobachtet wurde, während seine Peripherie mehr oder weniger durchsichtig blieb. Endlich verloren die Contouren die gleiche Sichtbarkeit und eŗschien die äussere dunkel, äusserst scharf, die innere hingegen undeutlieh und nur in einer gewissen Focusweite sichtbar. Sämmtliche hier beschriebene mit den Blutkörperchen unter der Einwirkung des salpetersauren Silbers vor sich gegangene Veränderungen konnte man im Lanfe einer Stunde beobachten. Auf den zweiten Tag in der feuchten Camera 
gelassen, behielt eine solche Mischung die angeführten Formen nicht mehr; im Gegentheil, der grösste Theil der Blutkörperchen wurde in ibrem Umfange bedeutend verkleinert und noch mehr erblasst vorgefunden. Die doppelten Contouren der Zellenmembran und des Zellenkerns waren verschwunden und die Abzeichnung der Blutkörperchen konnte man nur bei einer gewissen Lage des Focus und bei einer sebr starken Vergrösserung wahrnehmen. Einige von den Blutkörperchen fand man in eine körnige Masse zerfallen vor, oder sie zeigten eine sehr unregelmässige Form; die Zwischenräume der Blutkörperchen waren von mikroskopischen, structurlosen Fibringerinnseln besäet. Eine Peptonlösung des salpetersauren Silbers und das doppelte Silbersalz riefen bei ihrer unmittelbaren Einwirkung auf das Blut ausserhalb des Organismus ähnliche, aber nicht ganz dieselben Veränderungen hervor.

2) Die Wirkung einer Lösung des doppelten Silbersalzes a f die Blutkörperchen.

Unter dem Einflusse eines doppelten Silbersalzes erbielten die Blutkörperchen mehr oder weniger schnell, je nach der Concentration der Lösung ebenfalls doppelte Contouren; jedoch weniger ausgesprochen, als es in den Versuchen mit dem salpetersauren Silber der Fall war. Einige Zeit nach dem Beginn des Versuches (5-10 Minuten) wurden die erwähnten Contouren noch feiner, zu gleicher Zeit aber auch deutlicher und traten bei einer gewissen Focusweite in der Gestalt von glänzenden, gelblichen Ringen auf. Die Zellenkerne nahmen eine längliche oder eine runde Form an und waren von einer Schicht feinkörnigen Protoplasmas umgeben. Der peripherische Ring und der leicht gelb gewordene körnige Theil der Zelle machten sich bei der ferneren Einwirkung der Lösung (nach Verlauf einer halben Stunde) noch kenntlicher, während der innere Ring und die den Zellenkern unmittelbar umgebende körnige Mạsse allmählich immer zarter wurde, bis die Zellen ibre doppelte Contour gänzlich verloren zu haben schienen; jedoch lionnte man den Ring trotz seiner Zartheit bei einer gewissen Stellung des Brennpunktes und einer stärkeren Vergrösserung deutlich sehen. Die Zellen nahmen gewöhnlich die runde Form an. Das Protoplasmá des Zellenkernes wurde immer blasser und die körnige Masse um denselben vermehrt. Endlich erschien in dem Gesichtsfelde 
zwischen den Zellen eine kleinkörnige Masse (Fibringerinsel), welche. allmählich die auf dem Boden der feuchten Camera sich setzenden Blutkörperchen umfassten.

3) Die Wirkung des Silberpeptonats auf die Blutkörperchen.

Die erste Erscheinung, die sich zunächst unter dem Mikroskope nach Zuthat einer Lösung des Silberpeptonats zu einem Tropfen Blut bemerkbar machte, war, eben wie in dem vorangegangenen Versuche, das Hellwerden des Protoplasma und das deutliche Her. vortreten des Zellenkerns. Das Hellwerden wurde mit der Zeit immer bedeutender (im Laufe von 20-30 Minuten) und die Contouren immer zarter und feiner. Nur bei sehr aufmerksamer Beobachtung war es möglich, bei einer gewissen Focusweite den sehr zarten Ring der Zelle wahrzunehmen. Die weissen Blutkörperchen zeigten keine besonderen Veränderungen, ausgenommen ein leichtes Trübewerden. Ihr feinkörniges Aussehen ist vollständig normal; der Kern trat wie vorhin sehr deutlich hervor. Die Tags darauf unternommene mikroskopische Untersuchung der Mischung von doppeltem Silbersalz mit Blut zeigte folgende Veränderungen: Undeutlichkeit der früheren doppelten Contouren; das. Protoplasma der Blutkörperchen war noch mehr entfärbt und die Intercellularsubstanz der Blutkörperchen zeigte eine leicht gelbe Färbung und enthielt eine grosse Menge Fibringerinsel. Aehnliche Veränderungen wurden an diesem Tage auch in den Blutkörperchen des mit einer Peptonatlösung des salpetersauren Silbers vermischten Blutes beobachtet. Nur zeigten die Blutkörperchen dieser Mischung keine so erhebliche Formveränderung, wie wir dieselbe bei der unmittelbaren Beimischung des salpetersauren Silbers in das Blut zu sehen bekommen haben; ebenso waren die doppelten Contouren sehr undeutlich wahrzunehmen. Das Protoplasma der Blutkörperchen war noch mehr entfärbt. Die weissen Blutkörperchen waren ganz unversehrt geblieben. Die Zwischensubstanz enthielt noch keine Fibringerinsel, während in den Mischungen des Blutes mit doppeltem Salze oder salpetersaurem Silber die Gerinnung des Fibrins bereits eingetreten war.

Am dritten Tage hatten die Blutkörperchen, wie oben, unregelmässige Formen und äusserst feine, schwer wahrnehmbare 
Contouren. Die Blässe der Blutkörperchen ist vermehrt, jedoch behielten mehrere von ihnen eine schwache gelbe Schattirung. Die weissen Blutkörperchen erlitten keine Veränderung, nur dass sie aufgequollen waren. Das feinkörnige Ansehen erhielt sich vollständig. Die Zellen der Peptonlösung erschienen an diesem Tage in der Form verändert, indem sie vollständig durchsichtig wurden und die äusseren Contouren deutlicher ausgesprochen waren. Die weissen Blutkörperchen zeigten auch diesmal keine Veränderung. Sie waren überdies in grosser Menge beobachtet worden. Bei stärkerer Vergrösserung (7. System) konnte man einen sehr feinen doppelten Ring wahrnehmen.

Am vierten Tage ergab die mikroskopische Untersuchung der Mischung von Blut und doppeltem Salze keine neuen Veränderungen in den rothen Blutkörperchen; die weissen dagegen wurden noch dunkler und aufgequollener. Dasselbe kann man auch in Bezug auf die Mischung des Blutes mit der Peptonlösung des salpetersauren Silbers sagen. Ueberall wurde schon im Gesichtsfelde des Mikroskops eine grosse Menge der kleinkörnigen Masse von Fibringerinnsel beobachtet.

In den nachfolgenden Tagen betrafen die Veränderungen in den Blutkörperchen des mit doppeltem Silbersalze gemischten Blutes hauptsächlich ihre Form und die Beschaffenheit des Protoplasma. Letzteres war völlig farblos geworden, wobei die Blutkörperchen so feine Contouren bekamen, dass man diese nur bei äusserst aufmerksamer Beobachtung und bei einer gewissen Focusweite zu sehen im Stande war; bei einer stärkeren Vergrösserung (7. System) sah man sogar zickzackförmige Unebenheiten der Contouren, und dabei zeigte eine grosse Anzahl von Blutkörperchen schr unregelmässige Formen. Die Blutkörperchen aus der Mischung mit dem Peptonat des Silbers hingegen behielten noch immer ihre Contouren und ihre Form. Die Entfärbung des Protoplasma wurde wie vorhin beobachtet. Weisse Blutkörperchen konnte man im Gesichtsfelde des Mikroskops nicht finden und es war auch weder in der einen nocb in der anderen Mischung der mindeste Grad von Zersetzung des Blutes bemerkt worden. Alle hier eben angeführten Veränderungen wurden in den Blutkörperchen des zum Vergleiche unter ähnlichen Umständen stehen gelassenen Blutes nicht beobacbtet. An ihrer Form erlitten die Blutkörperchen fast keine Veränderung. 
Das Protoplasma war noch immer, wie gewöhnlich, gelb gefärbt und die Blutkörperchen besassen keine doppelten Contouren. Bei der Untersuchung mittelst des Spectral-Apparates sah man keine Hämatinstreifen, welchen Dichtegrad das zu untersuchende Blut auch haben mochte; hingegen war der normale Hämoglobinstreifen sehr deutlich wahrnehmbar. Bei des mit dem Spectroskop angestellten Untersuchung des aus dem Heizen der mittelst Silber vergifteten Thiere entnommenen Blutes erhielten wir, nachdem es einige Stunden gestanden, im Spectrum, wie oben erwähnt, die ersten Anzeichen der Erscheinung des Hämatinstreifens. Um aber jeden Zweifel in Bezug auf die Richtigkeit dieser Thatsache zu beseitigen und uns von der Abhängigkeit der Erscbeinung des Hämatinspectrums von dem unter dem Einflusse des Mittels später eintretenden Uebergange des in das Plạsma ausgetretenen Hämoglobins im Hämatin positiv zu überzeugen, haben wir wiederholentlich die SpectralAnalyse der künstlich bereiteten Mischungen unternommen. $\mathrm{Zu}$ diesem Zwecke schlugen wir folgendes Verfahren ein:

In drei bereit gehaltene Gläser, von denen das erste eine Lösung von $1 \mathrm{Grm}$. Doppeltsilbersalzes, das zweite 0,1 von demselben Salze und das dritte 0,5 salpetersauren Silbers auf 30,0 Peptonlösung enthielt, liessen wir aus der Arterie eines gesunden Hundes 60,0 Blut bei beständigem Umrühten hineinfliessen. Ein viertes Glas endlich enthielt zum Zwecke des Vergleiches normales Blut. Die mit dem Spectralapparat gleich nach der Bereitung unternommene Untersuchung ergab keinen characteristischen Hämatinstreifen, weder bei irgend einem Dichtegrade, noch bei der verschiedensten Verdünnung der Flüssigkeit.

Am Abend desselben Tages wurde die Untersucbung des Blutes mittelst desselben Apparates wiederholt, wobei sich Folgendes herausstellte: Die Mischung des Blutes mit der Lösung des Doppelsalzes zeigte bestimmt bei gewisser Concentration ein Hämatinspectrum, bevor noch die zwei bekannten characteristischen grünen Streifen in dem dunkeln Lichte des normalen Blutspectrum wahrzunehmen waren. Bei fernerer Verdünnung jedoch ersehien das normale Spectrum. Die Mischung des Blutes mit der Peptonlösung des Silbers sowohl, als auch das normale Blut, welches zur Vergleichung gelassen war, gaben bei keinem Dichtegrade ein Hämatinspectrum, hingegen zeigte sich bei einem gewissen Grade der Verdünnung das normale Spectrum des Blutes. Das mit einer Doppeltsilbersalzlösung vermischte Blut gab bei einer Verdünnung mit einer gleichen Menge Wasser desgleichen einen deutlichen Hämatinstreifen auch am zweiten Tage der Untersuchung und zwar war das Hämatinspectrum in dem gegebenen Falle sebr ausgesprochen. Bei Verdünnung von $1 \mathrm{Ccm}$. dieser Mischung mit $10 \mathrm{Ccm}$. Wasser konnte man immer das Hämatinspectrum sehen, wenn auch der characteristische Streifen sich in diesem Falle blasser zeigte. Bei der Untersuchung der Mischung von Blat mit den Peptonaten 
des Silbers konnte man in einer Mischung von $1 \mathrm{Ccm}$. Blat mit $8 \mathrm{Ccm}$. Wasser nur eine Andeutung von dem angeführten Streifen des Hämatinspectrum bemerken. Das zur Vergleichung gelassene normale Blut zeigte nichts Aehnliches.

Die Untersuchung am dritten Tage. - Das mit der Doppelsilbersalzlösung vermischte Blut zeigte noch immer ein Hämatinspectrum. Eine mehr concentrirte Mischüng des Blates mit demselben Salze gab ein ungleich deutlicheres Spectrum, selbst bei dem Grade der Verdünnung, bei welchem sich schon die zwei characteristischen Streifen des Hämoglobinspectrums zu zeigen begonnen hatten, so dass bei einem gewissen Grade der Verdünnung man zu gleicher Zeit ein doppeltes Spectrum, - das des Hämoglobin und das des Hämatin - wahrnehmen konnte.

Das mit der Peptonlösung gemischte Blut gab auch jetzt nur eine Andeutung von einem Hämatinstreifen. Das Blut aus allen Mischungen zeigte noch keine Zeichen der Zersetzung. Das unter denselben Bedingungen stehen gelassene normale Blut ergab keine der angeführten Veränderungen.

Die Reihe der angeführten Versuche beweist unzweifelhaft den unmittelbaren Einfluss der Silbersalze auf das Blut. Ihre Wirkung concentrirt sich hauptsächlich auf die Blutkörperchen, welche in Folge dessen das im Plasma sich auflösende Hämoglobin einbüssen, wodurch das Blut lackfarben wird. Das Protoplasma der Blutkörperchen entfärbt sich und in den Blutzellen selbst bemerkt man sowohl eine qualitative Veränderung des Inhalts, als auch eine Veränderung hinsichtlich der Form - je nach der Eigenschaft des gebrauchten Salzes und seiner Concentration. Das so ausgetretene Hämoglobin erleidet bernach eine fernere, frejlich äusserst langsame chemische Veränderung, indem es in Hämatin übergeht. Das Hämoglobin wird vermindert und es entsteht Anämie. Dieser Thatsache entsprechend magern die Thiere vom anhaltenden Gebrauch des Silbers ab und werden anämisch. Zur Bestätigung dessen unternahmen wir eine Reihe von Versuchen, welche den Zweck hatten, mittelst eimer vergleichenden Analyse die quantitativen Verhältnisse des Hämoglobins vor und nach der andauernden Fütterung der Thiere mit Silber festzustellen. Das Hämoglobin erbielten wir nach der in den "Annalen der Chemie und Pharmacie, 1866. Heft 2"' beschriebenen Methode von Preyer.

Wir nahmen nun ein Kaninchen, dessen normalen Globulingebalt wir nach der Formel $x=k\left(\frac{w+b}{b}\right)$, wo $k$ die normale Globulinmenge, $w$ die Menge des zugesetzten Wassers und b die Menge des genommenen Blutes bezeichnen, bestimmt hatten. Derselbe betrug $8,8 \mathrm{Grm}$. auf 100 Theile Blut. Das für den Versuch gewählte Kaninchen wog $1202 \mathrm{Grm}$. Hernach wurde das Kaninchen täglich mit einem Al- 
buminat des salpetersauren Silbers in Dosen von 0,05 bis $0,5 \mathrm{Grm}$. gefüttert. Während der ganzen Zeit der Beobachtung behielt das Kaninchen seinen Appetit, magerte aber merklich ab, täglich an seinem Gewicht abnehmend. Seine Excremente wurden gegen Ende der Beobachtung weich und chocoladenfarbig. Von Zeit zu Zeit traten Lähmungserscleinungen in den Extremitäten auf. Am 36. Tage hatte das Kaninchen an seinem Gewichte $222 \mathrm{Grm}$. eingebüsst, nachdem es $2,93 \mathrm{Grm}$. des Silberalbuminats verbraucht hatte. Am selben Tage wurde die Untersuchung auf Hämoglobin wiederholt und betrug sein Gehalt auf 100 Theile nur $5,44 \mathrm{Grm}$.

Zu gleicher Zeit wurde von uns der Versuch in Bezug auf das Verhältniss des Mittels zu dem quantitativen Globulingehalte auch mit einem Hunde geführt, der aber kein Silberalbuminat, sondern Doppeltsilber-Natronsalz bekam. Die Hämoglobinmenge vor Anfang des Versuches betrug $13,12 \mathrm{Grm}$. auf 100 Theile Blut. Der Hund erbielt tăglich das Doppeltsilbersalz, innerlieh, gemischt mit 1 Pfunde Fleisch und $\frac{1}{2}$ Pfande Brod. Dabei konnte er nach Bedürfniss und Belieben Wasser trinken. Mit den dargereichten Dosen des Silbersalzes wurde allmählich von 0,1 $\mathrm{Grm}$. bis zuletzt auf $0,3 \mathrm{Grm}$. gestiegen. Anfangs frass der Hund diese Mischung nur ungern, später nahm er indess ohne Umstände die grössten Dosen zu sích. Die wäbrend des Versuches sich kundgebenden Veränderungen waren den bei dem Kaninchen beobachteten durchaus ähnlich. Der Hund magerte gleichfalls $a b$, ungeachtet des Appetites, den er bis zu Ende behielt. Seine Körpertemperatur verminderte sich un einige Zehntel Grad. An die Stelle der anfangs vorhandenen Verstopfung traten wiederholentlich weiche Entleerungen ein. Am 46. Tage dieser Fütterung war die Globulinmenge in 100 Theilen Blat, nach Verbranch -von 13,28 Gramm des doppelten Salzes, gleich 8,78 Gramm.

Jetzt war es natürlich von besonderem Interesse, zu erfahren, ob das Silber bei anhaltendem Gebrauche nicht in die Blutkörperchen trete und die Verringerung der Gehaltsmenge an Globulin, folglich also auch des Eisens, nicht mit der chemischen Einwirkung der Silbersalze auf die Blutkörperchen in Verbindung stehe, und endlich, ob nicht etwa das Silber an die Stelle des Eisens tritt.

Um diese Frage zu lösen, unternahmen wir folgenden Versuch:

Am 35. Tage der Fütterung mit Silber wurde dem Hunde, der bereits 7,2 Grm. Doppelsalz verzehrt batte, 1 Unze Blat entnommen und diese mit 2 Unzen einer 4pracentigen sauren phosphorsauren Natronlösung gemischt; diese Mischung darauf 36 Stunden ruhig stehen gelassen.

Da das phosphorsaure Natron die Eigenschaft besitzt, die Bildung des Fibrins zu verhindern, den Farbstoff des Blutes dagegen nicht im Mindesten auflöst (Masia, dies. Arch. Bd. 34. 1865. November), so fielen alle Blutkörperchen ganz zu Boden und das Plasma war vollstundig durchsichtig geblieben. Die durchsichtige Schicht wurde mittelst einer feinen Pipette abgenommen und durch Centrifugalkraft der Rest des Plasma aus der gebliebenen rothen Schicht gepresst, und wir erhielten auf diese Weise die Bluthörperchen völlig von dem Plasma geschieden. Darauf wurde die 
zurückgebliebene rothe Masse über Gas in einem Platintiegel verbrannt und in der erhaltenen Asche nach Silber geforscht. Das Resultat dieser Forschung war ein negatives; wir fanden keine Spur von Silber vor und kamen in dieser Hinsicht zu demselben Schlusse wie Schumowsky, der den Gelualt von Metallen (Silber, Blei, Kupfer, Zink) in den Blutbörperchen dadurch bestimmt hatte, dass er das Blut mit den Albuminaten aus den angeführten Metalien gemischt und das Härmatin mittelst angesäuerten Weingeistes ausgescbieden batte.

Aus den oben angeführten Beobachtungen kann man folgende. allgemeine Thesen herausfolgern:

1) Das Silber wirkt auf das Blut entschieden antiplastisch, wobei es das letztere in Folge des allmählichen Ueberganges des im Plasma aufgelösten Hämoglobins in einem galligen Pigment flüssiger, dunkler, leicht infiltrirbarer Ergüsse und Ecchymosen bilden und bei andauernder Wirkung chlorotisch macht.

2) Die Blutkörperchen, indem sie unter dem Einflusse des Silbers ihr Hämoglobin an das Plastna abgeben, werden durchsichtig, blass und zeigen verschiedenartige qualitative Veränderungen (Durchsichtigkeit, Ungleichartigkeit in der Färbung, Körnigkeit) und Veränderung in der Form (die ovale längliche Form, die Erscheinung eines doppelten Contours).

3) Das Hämoglobin der Blutkörperchen ging allmählich in Hämatin und letzteres in einen gelben Farbstoff über, in Folge dessen die Gallenblase beständig von einer dunkelgrünen Galle ausgedehnt ist.

4) Die Menge des Hämoglobin-Gehaltes im Blute wird unter dem Einflusse des Silhers verringert.

5) Das Silber geht, wie es scheint, nicht in die Blutkôrperchen über, was früher bereits von Schumowsky beobachtet worden ist.

Alle diese Veränderungen treten, je nach der Beschaffenheit des Silbersalzes, welches auf das Blut eingewirkt hat, mehr oder weniger deutlich hervor; das reine salpetersaure Silber ubt in dieser Hinsicht den stärksten Einfluss aus. Ihm folgen dann das DoppeltSilbersalz und die Peptonate.

Die Veränderungen im Blute und seine Oxydation sind bekanntlich eng mit dem Bau und der Bildung der. Gewebe verbunden. Um die materiellen Veränderungen in dieser Hinsicht zu bestimmen, wurde an Kaninchen die folgende Reihe von Versuchen angestellt, von denen wir nur einige anfüren wollen. 


\section{Beobachtung 1 .}

Während des Lebens: Die Eintührung von 3,04 Grm. Doppeltsilber-Natronsalzes in den Körper eines Kaninchens in 4,47 Standen mittelst subcutaner Injection in Dosen von 0,01 bis 0,1 Gra. zeigte eine Temperaturverminderung um einige Zehntel Grad, ferner Schwankungen im speciflschen Gewichte des Urins und Erscheinen von Eiweiss in demselben; ferner Bestehen des Appetits während der ganzen Zeit der Beobachtung und die Entdeckung von Silber in den Excrementen. Endlich Entwickelung von Lähmungserscheinungen einige Tage vor dem Tode. Der Tod selbst trat in Folge von Erschöpfung ein.

Die Obduction wies Folgendes nach: Die harte Hirnhaut war an der inneren Fläche des Schädels fest angewachsen; in den Sinus fand sich eine nicht erhebliche Menge Blut; die weiche Hirnbaut anämisch, die Hirnsubstanz feucht, glänzènd, zähe, consistent, die Gefässe der Hirnhaut wenig mit Blut gefüllt. Das Fett war unter der Haut vollständig geschwunden, die Muskeln blass und wässerig, in den beiden Pleurasä̀cken wurde die Ansammlung einer serösen, völlig durchsichtigen Flüssigkeit vorgefunden (Hydrothorax); die linke Lunge bedeckt mit kleinen fibrinösen Fädën. Im Pericardium war ungefăhr 1 Drachme ähnlicher seröser Flüssigkeit enthalten, das Herz von gewöhnlichem Umfange, in der linken Vorkammer, besonders aber in der rechten, befinden sich ziemlich consistente dunkelrothe Blutgeriansel, die Lungen collabiren hei Eroffnung des Thorax. Sie besitzen eine grünlich-rothe Färbung, die stellenweise in eine graulich-gelbe äbergeht. An diesen letzteren Stellen bemerkt man unter der Pleura bedeutend erweiterte Lungenbläschen. Das Lungenparenchym erscheint blutarm. Die Leber ist gewöhnlichen Umfanges, dunkelbraun-röthlicher Farbe; auf der Durcbschnittsfäcbe tritt dunkles verdünntes, mit Gerinnseln gefülltes Blut ans. Das Gewebe der Leber fühlt sich fest an und stellenweis werden auf deren Oberfläche gelbe Punkte und Streifen bemerkt; ähnliche gelbe Stellen sind auch auf der Schnittfläche zu sehen. Die Gallenblase ist bis zur Grösse einer türkischen Bohne ausgedehnt und es ergiesst sich von derselben eine völlig durchsichtige gelblich-grüne Galle. Die Nieren sind von gewöhnlicher Grösse, grau-violetter Farbe; ihre Kapsel lässt sich leicht abziehen. Auf dem Durchschnitt sind sie gelblich-violett. Die Rindensubstanz ist grauschattirt, die Glomeruli gewöbnlicher Grösse und treten deullich anf der OberGäche hervor. Die venösen Gefässe der Marksubstanz sind mit Blut überfüllt; dasselbe ist auch mit den Nierenvenen der Fall, ferner mit den Hohlvenen und den Venen des Mesenteriums. Das Letztere ist fettarmer geworden; der Darm, besonders der Dickdarm, zeigt an seiner Aussenfläche eine graurothe Farbe. Die innere Fläche des Magens ist mit einer Schicht zähen Schleims bedeckt, und die Schleimbaut zeigt die Symptome eines chronischen Katarrhes (eine schiefergraue Farbe, Auflackerang and die Anwesentieit einer bedeutenden Menge Schleims). Der Schleimüberzug des Dänn - und Dickdarms besitzt dieselbe schiefergrauliche Färbung, die in ihnen enthaltenen halbflüssigen Excremente sind chocoladenfarbig. In der Harnblase befinden sich circa 2 Drachmen trüben. Urins. Die grauliche, duakle Färbung der Rindeasubstanz der Nieren war, wie die mikroskopische Untersuchung erwiesen hat, durch die Auflockerung und Verdunkelung des Epithels der Harnkanälchen 
dieses Nierentheiles entstanden. Die Muskeln des Herzens zeigten folgende Veränderungen: in der Mehrzahl der Fasern konnte man weder die Streifung noch die Zellenkerne bemerken. Sämmtliche Fasern waren mit einer sehr grossen Anzahl feiner Körnchen besäet. Bei Zusatz von Essiggäure schwinden diese dunklen Körner, die Muskelfasern schimmern durch ynd fangen an sichtbar zu werden. Die Kerne der letzteren sind in der Zahl vermehrt; ebenso treten auch die Längsstreifen deutlicher als die Querfasern hervor. Die Dicke der aus dem Oberschenkel entnommenen Muskelfasern ist wie gewöhnlich, aber ihre Querstreifung ist in der Mehrzahl der Falle nicht so deutlich zu seheb, und im Algemeinen zeizen die Fasern dieser Muskeln unter-dem Mikroskope dieselben Veränderungen, wie diejenigen des Herzens, indem sie ebenfalls ron dunklen Körnchen besầt sind, welche der Einwirkung von Essigsäure weichen. Was die interstitiellen Bindegewebe betrifft, so zeigen sie eine schleimige Umbildung (das Zuthun von Essigsäure lässt díe Sternform der Zellen mit den langen Auswüclssen deutlich bervortreten); die Zellen der Leber sind trübe und aufgeschwellt. Sowohl die Centralvene der Läppchen wie auch die Vene zwischen den letzteren sind vom Blute ausgedehnt. Das Trübwerden der Zellen verbreitet sich gleichmässig vom Centrum nach der Peripherie zu.

\section{Beob a chtung II.}

Während des Lebens: In 39 Tagen wurden auf dem Wege der subcutanen Injection 3,14 Grm. Doppeltsilber-Natronsalz in Dosen von 0,01 bis $0,1 \mathrm{Grm}$. dem Organismus zugeführt. Temperaturverminderung um einige Zehntel Grad Celsius. Vorübergehende Appetitlosigkeit in den ersten Tagen des Versuches. Das Erscheinen von Eiweiss im Urin. Steigen des specifischen Gewichts des Harns. Auftreten von Lähmungserscheinungen in den Extremitäten einige Tage vor dem Tode. Weiche, chocoladenfarbige Excremente. Verminderung der Urinmenge. Am 33. Tage der Beobachtung Auftreten von Lähmungserscheinungen nach erfolgter Einspritzung einer verhältnissmässig grösseren Dosis. Tod durch Erschöpfung.

Die Section. Die plötzlich eingetretene Todesstarre schwand im Lanfe von 6 Stunden und hielt sich nur in den Kaumuskeln und zum Theil in den oberen Extremitäten. Bei Eröffnung der Schädelhöhle liess sich die harte Hirnhaut leicht von der inneren Schädelwand abnehmen. Das Parenchym des Gehirns und seiner Häute war blutarm. Das Gehirn ist, wie in den vorangegangenen Beobachtungen glänzend und auf der Durchschnittsfläche treten keine rothen Pünktchen auf. Eine ähnliche Erscheinung ist im Rückenmarke bemerǩt worden. Das Kaninchen bietet ein Bild allgemeiner Abmagerung dar: das Unterhantfettgewebe ist fast ganz geschwunden, die Muskeln sind blass und wässrig, in den Pleurasäcken befindet sich eine geringe Menge Flüssigkeit. Die Lunge ist orangeroth gefärbt und lufthaltig; beim Einschneiden tritt auf die Schnittfläche eine geringe Menge blutig-seröser Flüssigkeit; die unteren Lappen sind byperämisch, die unteren und mittleren Lappen bieten Symptome eines Emphysems. Das Herz ist seiner Grösse nach normal und von gelblich-brauner Färbung. Die rechte Herzkammer ist mit fibrinösen Gerinnseln und zum. Theil mit flüssigem Blut angefüllt, die linke Herzkammer ist leer, ihre Wandungen comprimirt. In der Herzbeutelhöhle befindet sich eine unbedeu- 
tende Menge Flüssigkeit. Die Aorta ist leer, die beiden Hohlvenen, wie auch die Venen des Mesenteriums und des Pankreas sind mit danklem halbgeronnenem Blute überfüllt. Die Leber ist normaler Grösse, mit deutlich ausgesprochener Lobularität und gelbbrauner Farbe; im linken Lappen ist diese Farbe am deutlichsten ausgesprochen. Beim Einschneiden tritt flüssiges Blut heraus. Die Gallenblase bietet eine birnenförmige Gestalt und ist stark ausgedelnt, die Nieren sind normaler Grösse, ihre Kapsel lässt sich leicht abzieben, von aussen sind sie grau-violett. Beim Durchschnitt erscheint die Marksubstanz dunkler gefärbt, als die Rindensubstanz. Letztere ist auch blutarmer. Die Milz ist normaler Grösse: Der Magen ist mit einer geringen Menge Speisereste gefüllt und seine Schleimhant bietet das Aussehen eines Katarrhs; im Pankreas und im Netz ist kein Fett mehr vorhanden. Die Schleimbaut des Dünndarms ist blass und dieser letztere enthält keinen Chymus. Der Dickdarm dagegen ist mit braungefärbten Excrementen angefüllt. Die Muskeln des Herzens zeigen unter dem Mikroskop keine Abweichung von der normalen Beschaffenheit, indess ist die Querstreifung der Fasern nicht so deutlich wie sonst ausgesprochen. Dasselbe kann man auch von den anderen Muskeln des Körpers sagen.

Den gelblich gefärbten Stellen der Leber entsprechend, lassen sich unter dem Mikroskop folgende Erscheinungen wahrnehmen: Eine grosse Anzabl der Leberzellen enthält einen körnigen Inhalt, wobei die Zellenkerne vollständig unsichtbar werden, andere, z. B. Lungenzellen, erscheinen hingegen nur getrübt, was auf den Anfang der Entwickelung einer fettigen Metamorphose hindeutet. In dem Epithel der Bellini'sehen Röhrchen warden dieselben Erscheinungen der Schwellung und der Trübung beobachtet. Stellenweise finden sich Röhrchen mit Zellen, die bereits eine vollständige fettige Metamorphose erlitten haben, welche im Leben der Ausscheidung des Eiweisses entspricht.

\section{Beobachtung III.}

Während der 36. Tage des Experiments warden durch den Magen 2,35 Grm. Doppeltsilbersalz in Dosen von 0,05 bis 0,1 Grm. dem Organismus zugeführt. Die Gewichtsveränderung betrug $\frac{5}{10} \mathrm{Grm}$. Die Temperatur war um einige Zehntel Grad verringert. Der Appetit unveränderlich während der ganzen Zeit des Versuches. Das specifische Gewicht des Harns war schwankend, die Secretion beeinträchtigt. Dann zeigte sich Verstopfung und zeitweises Eintreten flüssiger Ex'cretion und zwar in den letzen Tagen der Beobachtung; einige Tage vor dem Tode traten Lähmungserscheinungen in den Extremitaten und Eiweiss im Urin auf. Zeitweise wurde auch die Fütterung mit Silber eingestellt. Der Tod trat durch Erschöpfung nach dem 36 . Tage ein.

Die Section. Allgemeine Abmagerung. Das Gehirn trägt Abzeichen der Blutarmuth. Beim Einschneiden treten keine rothen Punkte auf; die Hirnsubstanz ist blass, glänzend, zähe. In dem Sinus der harten Hirnhaut ist halbgeronnenes dunkel gefärbtes Blut enthalten, die weiche Hirnhaut ist anämisch und ebenso ist im Hirnmark mit Ausnahme der Anämie nichts Abnormes bemerkt worden. Beim Eröffnen der Brusthöhle fielen die Lungen in normaler Weise zusammen, ihre Farbe war dunkelrosenroth. In der Höhle des Pericardiums fand sich ungefähr 
1 Unze serōser Flüssigkeit. Das Herz war in seinem Unfange ein wenig verkleinert und gelblich-roth gefärbt. Seine rechte Hälfte ist mit flüssigem dunkelgefärbtem Blute gefüllt, die linke leer. Die beiden Hohlvenen enthalten zum Theil geronnenes, zum Theil flüssiges Blut. Die mikroskopische Untersuchnng der Herzmuskełn fährte anf folgende Veränderungen: die Querstreifung der Fasern war undeutlich und es zeigte sich auch hier in reichlicher Menge eine feinkörnige Masse, die, ebenso wie in den vorangegangenen Versuchen, der Einwirkung der Essigsäure wich, wobei gleichzeitig die Kerne des Sarcolemma dentlich hervortraten, ohne übrigens an ihrer Zahl die gewölnliche Norm zu übersteigen. Die Leber besitzt die gewöhnliche Grösse, ist hellbraun in's grau hinüberschillernd, ihre Läppchen treten dentlich hervor; beim Durchschneiden ergiesst sich in geringer Menge sehr flüssiges Blut. Der. graulichen Schattirugg der Leber entsprechend findet man unter dem Mikroskop Erscheinungen der trüben Schwellang der Epithelelemente; die Leberzellen sind mit dunklem körnigem Inbalt gefültt und die Zellenkerne sind nicht mehr zu unterscheiden. Die Gallenblase enthält circa 3 Unzen grüngefärbter Galle. Die Schleimbant des Magens und des Darmkanals befinden sich beide im Zustande des Katarrhs. Der Dünndarm ist leer, der. Dickdarm hingegen enthält im Ueberlusse chocoladenfarbige Excremente. Die Rindensubstanz der Nieren ist apämisch und erscheint graulich schattirt. Das Gehirnparenchym ist dagegen hypertrophisch. Im Einklange mit den makroskopischen Erscheinungen entdeckt das Mikroskop eine acute Anschwellung der Elemente der Bellini'schen Röbrchen (trübe Schwellnng nach Virchow), unter welchen mehrére im Zustande einer fettigen Degeneration sich befanden.

\section{Beobachtung IV.}

Während des Lebens. Im Laufe von 2 Monaten und 10 Tagen wurde einem Kaninchen $3,25 \mathrm{Grm}$. Doppeltsilbersalz von 0,01 bis $0,1 \mathrm{Grm}$. pro dosi zugeführt. Abmagerung am ganzen Körper, zeitweise Appetitlosigkeit in den ersten Tagen der Beobachtung, Temperaturyerminderung um einige Zebntel Grad. Zu Ende der Beobachtung Gewichtsverminderung um $242 \mathrm{Grm}$. Schwankung des speeifiseben Gewichts des Urins. In den Ietzten 3 Wochen vermehrte Stuhlausleerung von Lellbrauner Färbung, Entwickelang von Lähmungserscheinungen besonders in den hinteren Extremitäten. Algemeine Collapsus-Erscheinungen von Anämie. Tod in Folge von Erschöpfung am 70. Tage der Beobachtung.

Die Section. Das Fettgewebe der Haut, sowie im. Mesenterium, war vollständig geschwunden, die Muskeln des Rumpfes blass und blutarm. Das Parenchym des Gehirns zeigte, mit Ausnahme der Anämie, keine besonderen Erscheinungen. Die Sinus der Dura mater des Gehirns sind mit Blut gefüllt; die Gefässe der Pia hingegen ziemlich blutleer. Die Sinus transversi des Gehirns enthielten eine geringe Menge seröser Flüssigkeit. Die Hirnsubstanz jst elastiseh und fühlt sich ein wenig consistent an. Die Pia mater des Gehirns sowohl, wie die Dura mater sind anämisch. An dem Parenchym des Gehirns selbst war nichts Besonderes zu bemerken. Die Lunge ist lufthaltig, orangeroth und ohne Verdichtungen, der hintere Lappen war indess intensiv roth gefärbt. In der Höble des Pericardiums fand sich eine geringe Menge seröser Flüssigkeit; die Oberläche des Herzens hellbraun, gelb- 
lich schattirt; was sich besonders an dem leeren linken Ventrikel geltend machte; der rechte Ventrikel enthält im Gegentheil halbgeronnenes, theerfarbiges Blat. Die obere und untere Hoblvene, sowie die Venen des Mesenteriums, sind zum Theil mit Gerinnseln, zum Theil mit dunkelgefärbtem Blute gefültt. Die Muskeln des Herzens zeigen unter dem Mikroskope deutliche Anzeichen einer beginnenden fettigen Degeneration; bei der Mehrzahl der Fasern kann man weder die Quer- noch die Langsstreifung wahmehmen und alle sind bedeckt mit der oben besclriebenen feinkörnigen Masse. An die Stelle noch anderer Muskelfasern sind bereits Fettröpfchen getreten. Das Epithel der Bellini'schen Röhrchen ist nur ein wenig getrübt, sonst nichts Besonderes an ibnen zu bemerken. Die Leber ist in ihrem Umfange ein wenig verkleinert, an der 0berfläche erscheint sie gelbbraun, auf der Schnittfläche aber hellgelb mit gräulicher. Schattirung. Beim Einschmeiden ergiesst sich kein Blut; sie ist überhaupt blutarm. Der gelblichen Färbung der Leber entsprechend befinden sich ihre Zellen in einer fettigen Degeneration; ihre Form ist verändert, einige unter ihnen sind vergrössert und entweder mit Fetttröpfchen oder Fettkörnchen gefüllt. Die Gallenblase ist mit Galle äberfültt und a ausgedehnt, die Galle ist dunkelgrïn. Die Milz zeigt nichts Besonderes. Der Magen ist stark überfiillt mit der Speisemischung. Die Farbe seiner Schleimhaut ist blass, ein wenig graulich; die Schleimhaut selbst bedeckt mit einer Schicht von graulich-trübem Schleim, welcher fest an ibren Wänden anklebt. Der Dünndarm ist leer; sein seröser Ueberzug ein wenig rosafarbig. Die Nieren zeigen dem Ansehen nach nichts Abnormes. Die Gefässe des Gehirnparenchyors erscheinen unter dem Mikroskop gedebnt. Die Glomerali treten ziemlich deutlich bervor. Die Harnblase zeigte auf ilurer inneren Fläche die Anzeichen eines Katarrbs. (Schwellung and Succulenz der Schleimhaut und Vorhandensein von Schleim im Harn) und enthält circa $\frac{1}{2}$ Unze Urin, welcher kein. Eiweiss enthält, wie es während des Lebens der Fall war.

\section{Beobachtung $V$.}

Während des Lebens: In 26 Tagen der Versuchsfübrung wurde einem Kaninchen 3,5 $\mathrm{Grm}$. Doppeltsilhersalz in 0,05 bis $0,2 \mathrm{Grm}$. pro dosi zugeführt. Es traten ein vermehrte Absonderung des Urins und Verminderung seines specifischen Gewichts, Temperaturverminderung um einige Zehntel Grade, Auftreten von Eiweiss im Harn, Gewichtsverminderung des Körpers während der ganzen Zeit des Versuchs um 252 Grm., Schwinden des Appetits, 3 Tage vor dem Tode erschwerte Beweglichkeit, vermelrte Menge der Stuhlentleerungen, Braunwerden der Excremente, Anästhesie in den binteren Extremitäten, der Tod in Folge von Erschöpfungen unter vorangegangener Erscheinung von Erschlafung der Extremitäten. Die Obduction wurde nach 6 Stunden vorgenommen.

Die Section zeigte: Allgemeine Abmagerung, Schwund des Unterhautfettes, die Muskeln blass, die Dura mater anämisch, in ihren Sinus halbgeronnenes dunkelfarbiges Blut, die Gehirnsubstanz ebenfalls blutarm, glänzend, zähe. Auf dem hinteren Theile der rechten Hemisphäre sind dunkle Stellen zu bemerken (Spuren einer bestandenen Meningitis). Die Dura mater des Rückenmarks ist fest an den Wirbeln angewachsen; das Rückenmark selbst consistent; auf dem Querdurchschnitt geht die graue Substanz fast ohne deutliche Abgrenzung in die weisse über. Die 
Gefässe der Pia mater sind mässig. mit Blut gefüllt. Bei Eröffnung des Brustkastens fallen die Lungen zusammen. Letztere erscheinen orangeroth gefärbt und das Gewebe ist lufthaltig. Die hinteren Lappen sind hyperämisch und ecchymosirt; die Oberfäche dieser Lappen erscheint marmorirt. Beim Einschneiden der Lunge ergiesst sich eine durchsichtige, schaumige, mit Blut gemischte Flüssigkeit. Die innere Oberfläche der Luftröhre und ibrer Hauptzweige baben die Anzeichen eines chronischen Katarrhs. In den beiden Pleurasäcken Ansammlung einer geringen Menge Flüssigkeit. Eine ähnliche Flüssigkeit ist ịm Pericardialsack enthalten. Das Herz ist von gewöhnlicher Grösse, seine Oberfäche gelblich schattirt. Dieser gelben Schattirung entsprechend entdeckt das Mikroskop eine Trübung und eine Undeutlichkeit der Querstreifung der Muskelfasern und eine sehr grosse Menge einer körnigen Masse. Der rechte Ventrikel und die recbte Vorkammer sind mit halbgeronnenem dunklem Blute gefüllt. Eben solche Gerinnsel mit flüssigem Blute gemischt findet man in den beiden Hobivenen und in denjenigen des Mesenteriums. Der linke Yentrikel ist leer und erscheint contrahirt. Die Leber ist ebenfalls in ihrem Jmfange kleiner geworden, röthliebgran gefärbt und dabei deutlich gelblich schattirt. Dieser gelblichen Schattirong entsprechend zeigte sich unter dem Mikroskope eine fettige Degeneration der Leberzellen, von denen mehrere noch nicht vollständig in Fettkörncben zerfallen waren, sondern sich noch im ersten Stadium dieses regressiven Prozesses befanden. Die bereits verfetteten Zellen lassen keine Kerne mehr wahrnebmen. Ebenso triff man Zellen an, die in ihrem Umfange bedeutend verkleinert sind; sie erscheinen runzlig, da ihr fettiger Inhalt zum Theil der Resorption anheinfiel. Die Gefässe der Leberläppchen sind ungleichmässig gefültt. Die Gallenblase ist ausgedehnt und überfällt von einer grünen, völlig durchsichtigen Galle. Die Nieren simd gewöhnlicher Grösse, ihre Kapseln lassen sich leicht abziehen, die Rindenschicht ist graulich-dunkelbraun. Die Glomeruli sind sehr deutlich zu sehen. Die mikroskopische Untersuchung zeigte eine unbedeutende Trübung des Epithels der Bellini'schen Röhrchen und eine Hyperămie der Marksubstanz. Der Magen war mit Speise üherfüllt, seine Schleimhaut geschwollen uad mit einer Schicht von Schleim überzogen. Die Schleimhaut ist graulich, der Schleim bingegen graulich-gelblich gefärbt. Die mikroskopische Untersuchnng der Labdrüsen zeigte eine Anschwellung und Trübung ibrer Elemente. Einige von ilinen enthalten alle Anzeichen einer fettigen Degeneration. Der Dünndarm ist leer, der Dickdarm hingegen mit einer bedentenden Menge weicher hellhrauner Excremente angefüllt. Die innere Fläche des Dünndarms ist von blassgrünlicher Farbe und mit einer zähen Schleimschicht bedeckt. Die Peyer'schen Drüsen sind durch das Mikroskop leicht zu sehen. Die" Harnblase ist ausgedehnt und angefüllt mit einem halbdurchsichtigen, lockigen Urin, welcher eine geringe Menge Eiweiss entuält.

\section{Beobachtung VI.}

Im Leben: Im Laufe von 33 Tagen wurden in den Magen eines Kaninchens eingefülırt: 4,7 Grm salpetersauren Silbers in einer Peptonlösung, in progressiven Dosen von 0,05 bis $0,35 \mathrm{Grm}$. Gewichtsabuahme um $242 \mathrm{Grm}$., Sinken der Temperatur um einige Zehntel Grad. Verringerung des specifischen Gewichts des Drins. Auftreten von Eiweiss in demselben. Appetit unverändert. Zuerst Ver- 
stopfung, aber in den letzten Tagen des Lebens reichliche, weiche Stuhlausleerungen. Auftreten paralytischer Erscheinungen in den Extremitäten und Anästhesie derselben einige Tage vor dem Tode. Letzterer trat am 33. Tage der Beobachtung unter Erscheinungen allgemeiner Erschöpfung ein.

Section. Vollständiger Schwand des Unterhautfettes. Die Muskeln blass und im Zustande der Atrophie. Die Dura mater am Schädeldache angewachsen, ibr Sinus longitudinalis mit flüssigem dunkelgefärbtem Blute gefüllt. Die Gefässe der Pia mater deutlich gezeichnet. Die Hirnsubstanz mässig mit Blat gefüllt, die Sinus enthalten eine geringe Menge durchsichtiger Flüssigkeit. Die Dura mater des Rïckenmarks injieirt, ihre Gefässe erscheinen gescblängelt; die Pia mater zeigt ebenfalls eine bedeutende Injection. Das Parenchym des Rïckenmarks ist dem Ansehen nacb normal. Die Lungen rothorange gefärbt and vollständig lufthaltig. Beim Einschneiden derselben ergiesst sich in geringer Menge eine schaumige, rosigschattirte Flüssigkeit. In der Pericardialböhle ist eine unbedeutende Menge einer hellen serösen Flüssigkeit vorhanden. Das Herz ist von gewöhnlichem Umfange; der rechte Ventrikel, sowie das rechte Atrium zum Theil mit flüssigem, zum Theil aber mit geronnenem dunkelgefärbtem Blute gefüllt. Die beiden Hohlvenen, sowie die Mesenterica, sind stark mit halbgeronnenem dunklem Blut überfüllt. Die Leber ist um ein Drittel in ihrem Umfange verkleinert. Ibre Ränder erscheinẹn diunn und durchsichtig. Ihre Farbe dunkelbraun gelblich und stellenweise treten gelbliche Flecken und Streifen hervor; beim Einschneiden ergiesst sich flüssiges dankles Blut. Den gelblich gefärbten Stellen entsprechend, entdeckte die mikroskopische Untersuchung eine fettige Degeneration des grössten Theiles der Leberzellen. In einigen derselben ist die Yerfettung noch nicht so weit vorgeschritten und die Zellen erscheinen nur mit einem feinlörnigen trüben Inhalt, in welchem der Kera nicht zu unterscheiden ist. Noch andere Zellen enthalten feine Fetttröpfchen, in Folge dessen sie die Gestalt körniger Kügelchen erbalten haben. Die zwischen den Läppchen eingebetteten Gefässe erscheinen unter dem Mikroskop durch Blutanfüllung ausgedehnt. Die Gallenblase ist mit gelbgrüner Galle gefüllt, in welcber die chemische Untersuchung Silber constatirt hat. Die Nieren sind normalen Umfanges, ihre, Kapseln leicht lösbar; das Parenchym unter denselben erscheint braun mit einer deutlichen gelben Schattirung. Auf der Durchscbnittsfläche hebt sich die Rinden- von der Marksubștanz grell der Färbung nach ab; die erstere ist gelblichroth, die zweite hellgelb, und die Grenzen dieser zwei Felder sind deutlich markirt. Die Muskeln des Thorax zeigen unter dem Mikroskop folgende Erscheinungen: Die Querstreifen sind schwer zu unterscheiden, hingegen ist die Längsstreifung sehr deutlich ausgesprochen. Trotzdem ist die Mehrzahl der Muskelfasern mit einer bedeutenden Menge feiner Körnchen besâet, die beim Zngiessen von Essigsäure verschwinden und dann erscheinen die Zellenkerne in ibrer Zahl vergrössert. Dasselbe kann von den Muskeln des Herzens gesagt werden. Der dunklen Färbung und der gelblichen Schattirung der Rindensubstanz entsprechend, entdeckte die mikroskopische Untersuchung Ansehwellung nod Trübung des Epithels der Bellini'schen Röbrchea. Manche Epithelzellen haben ihre Form 'gewechselt and sind mit einer körnigen aus Fett bestehenden Masse gefüllt. Im Einklange mit diesem Zustande der Nieren wurde während des Lebens im Harn Eiweiss vorge- 
funden. Der Magen ist leer. Seine innere Fläche ist mit einer reichlichen graufarbigen Schleimschicht bedeckt; die Schleimhaut schieferfarbig und angeschwollen. Der Inhalt des Magens ist ebenfalls grau; der Dünndarm zeigt auf der der Bauchhöhte zugekehrten 0 berfläche eine merkliche Injection. Sowohl der Dünndam als der Dickdarm sind reicblich mit Koth gefült, während das Rectum vollständig leer ist. Die Milz ist annähernd um zwei Mal verkleinert, ihre Farbe blassrosig. Die Harnblase ist bis zur Grösse eines Gänseeies ausgedehnt; ibre Wandungen vollständig durchsichtig, so dass man durch dieselben die in dem Urin schwimmenden Flocken wahrnehmen kann.

\section{Beobachiung VII.}

Erscbeinungen im Leben. Nach vorangegangener Ermittelung der Hämoglobinmenge des Blutes des gesunden Kaninchens in einer gewissen Einheit wurden demselben 3,93 Grm. salpetersauren Silbers in der Form eines Albuminats im Laufe von 43 Tagen in Dosen von 0,05 bis $0,5 \mathrm{Grm}$. eingeführt. Es zeigte sich Vergrösserung des specifjsclen Gewichts des Harns. Gewichtsabnahme des Körpers 229 Grm. Vorhandensein des Appetits wäbrend der ganzen Zeit der Beobachtung. Wiederholte Untersuchung auf Hämoglohin mittelst eines Spectralapparates liess Verminderung der Hämoglobinmenge im Blute erkennen. Entwickelung paralytischer Erscheinungen einige Tage vor dem Tode. Tod durch Erschöpfung. Beeinträchtigung der electro-musculären Contractilität.

Section. Plötzlicher Eintritt der Todtenstarre (die Section wurde 1 Stunde nach dem Tode uuternommen). Das Unterhautfett vollstindig geschwunden. Die Muskeln in hohem Grade blass, atrophisch. Die Rückenmuskeln, welche sonst bei dem Kaninchen in der Richtung des Rïckens gewöhnlich in dicker Schicht aufliegen, sind vollständig geschwunden und statt ihrer konnte man auf der ganzen Fläche die Wirbel sammt ibren knöchernen Fortsätzen durchfühlen. Die Dura mater des Gehirns war im Zustande der Hyperämie. Die Sinus waren mit schwarzem, theils alüssigem, theils geronnenem Blute gefïllt. Das Hirnparenchym zähe, blass; auf der Schnittfläche traten selir wenig rothe Punkte auf. Die harte Haut des Rückenmarks zeigt ebenfalls einen Zustand der Blutstockung. Im Uebrigen bietet das Gehirn nichts Abnormes. Bei Eröfinung des Brustkastens fallen die Lungen normal zusammen. Ibre Farbe war in Folge von Pigmentablagerung (es war ein altes Kaninchen) ungleichmässig roth; in den hinteren Lappen der linken Lunge Erscheinungen der Hypostase und in der rechten Lunge finden sich bis birseliorngrosse Blutextravasate; an den vorderen Rändern Erscheinungen von Enphysem. Das Herz in seinem Umfange verkleinert. Die Höhle des Pericardium enthält bis zu Dr. 1 Liquor peric. Die mikroskopische Untersuchung der Muskelfasern des Herzens zeigte Folgendes: An die Stelle der gewöhnlichen quergestreiften Fasern tritt eine körnige Masse, die beinahe das ganze Gesichtsfeld des Mikroskopes einnimmt, jedoch lassen sich unter dieser Menge von Körnern auch eigentliche Muskelfasern mit einer schwach markirten Querstreifung entdecken. Die genannte Masse von Körnern schwindet fast vollständiğ nach Zusatz von Essigsäure, wobei auch die Kerne der Muskelfasern in scheinbar vergroosserter Zahl hervortreten. Die mikroskopische Untersuchung anderer Muskeln des Körpers constatirtêäanliche 
Veränderungen, jedoch nicht so deutlich ausgesprochen wie oben. Beide Herzhälften enthalten dunkles mit Gerinnseln gemischtes Blut. Dasselbe Blut findet man auch in den beiden Hohlvenen, sowie in den Venen des Mesenteriums. Die Leber ist in ihrem Umfange vergrössert und hypertrophisch, graubraun. Beim Einschneiden ergiesst sich dunkles flüssiges Blut ohne Gerinasel. Die Gallenblase enthält eine geringe Menge graugefärbter Galle. In den Leberzellen findet man viele ziemlich grosse Fetttröpfeben, von denen manche trübe geworden sind. Die interlobulären Verzweigungen der Pfortader erscheinen unter dem Mikroskope gedehnt. Die Nieren sind gewöhnlicher Grösse und gelbbrauner Färbung; die Marksubstanz hypertrophisch. In den epithelialen Elementen der Bellini'schen Röhrchen konnte das Mikroskop keine Abweichung von der Norm entdecken. Der Magen ist mit Speise gefüllt, die Schleimhant desselben ist katarrhalisch afficirt und mit einer Schicht zäben Schleims überzogen. Der Dünndarm enthält eine geringe Menge von Excrementen, seine Schleimhaut ist ebenfalls vom Katarrh befallen. Die Urinblase ist von einem halbdurchsichtigen Urin ausgedehnt, in welchem herumschwimmende Schleimgerinusel wabrnehmbar sind.

Aus allen diesen Resultaten, welche über die bei andauerndem Gebrauche dieses Metalls im Baue der Organe entstehenden Veränderungen gefunden worden sind, seheint es uns erlaubt, folgendes Riesumé zu ziehen:

1) Die Quantität des Harns war in der Mehrzahl der Fälle verringert, während das specifische Gewicht desselben sich gleichzeitig vergrösserte, ebenso waren die Excretionen bedeutend vermehrt und dunkelgelb oder chocoladenfarbig gefärbt.

2) Die Temperaturschwankungen sind nicht erheblich zu nennen, dem ungeachtet géhörte die Temperaturverminderung um einige Zehntel Grad zu den fast constanten Erscheinungen, sowohl der acuten, als auch der chronischen Einwirkung des Silbers.

3) Aus der Gruppe der Silbersalze übte das doppelte Natronsalz wegen seiner grösseren Resorptionsfähigkeit die intensivste Wirkung auf den Organismus aus. Die Kaninchen, denen dieses Salz auf dem Wege der subcutanen Injection in Dosen von 0,01 bis 0,1 zugeführt worden ist, starben durch Erschöpfung, wie es oben aus den angeführten Beobachtungen zú ersehen ist, annähernd am 40. Tage der Beobachtung, nachdem sie durchschnittlich 3,01 Grm. dieses-Salzes verbraucht hatten. Durch den Magen aufgenommen in Dosen von 0,01 bis 0,5 Grm. führte es ungefähr am 46. Tage, nach Verbrauch von durchschnittlich 2,12 Grm. zum Tode.

4) Nächst dem Doppelt-Silbersalze sind der Intensität der Einwirkung nach die Peptonate und die Albuminate des salpetersauren 
Silbers zu nennen, sodann das reine salpetersaure Silber. Die anderen Salze dieses Metalls, als weniger lösliche, verhielten sich schwächer zum Organismus. Das Peptonat des salpetersauren Silbers und das Albuminat riefen, in den Organismus in Dosen von 0,05 bis 0,5 eingeführt, den. Tod des Kaninchens annähernd am 43. Tage der Beobachtung herbei und zwar nach Verbrauch von durchschnittlich 4 Grammes des Mittels. Das reine salpetersaure Silber tödtete diese Thiere um dieselbe Zeit bei Einführung in den Organismus durch den Magen von 6,28 Gramm in einzelnen Dosen von 0,05 bis 0,5 Gramm. Im letzteren Falle concentrirte sich die Wirkung dieses Salzes hauptsächlich in der Schleimhaut des Magens (Bildung eines Schorles) und nur ein verhältnissmässig geringerer Theil ging in Form eines Silber-Peptonats, im Falle in dem Magen die Bedingungen zu dessen Bildung vorhanden waren, unmittelbar in das Blut über.

5) In dem Organismus angelangt, rief das Silber materielle Veränderungen in dem Baue der Organe hervor; und diese Veränderungen concentrirten sich hauptsächlich, wie wir oben gezeigt haben, jm Blute, sodann machten sie sich in den Schleimhäuten oder ihren analogen Geweben geltend:

a) Der Schleimhautîiberzug der Luftröhren, sowie des Darmkanals wurde bei andauerndem innerlichen oder subcutanen Gebrauche des Mittels katarrhalisch angegriffen. In den EpithelialElementen der beiden grossen Drüsen, der Leber und den Nieren wurde wiederhalt unter dem Einflusse des Silbers die Entwicklung eines diesen Gebilden eigenthümlichen Prozesses beobachtet.

b) Die Leberzellen und das Epithel der Bellinischen Röhrchen befanden sich grösstentheils im Zustande der trüben Schwellung (Trübung des Inhaltes derselben, vergrösserter Umfang der Elemente und undeutliche Markirung des Kerns in Folge davon) oder sie verfielen in eine fettige Degeneration (das Vorhandensein von Fettkörnern in den Zellen, Verschwinden des Kerns derselben, Umwandlung in dunkle körnige Kügelchen, Resorption von Fett). Die Leber wurde bei der Section bald mit Blut überfüllt und in ihrem Umfange vergrössert gefunden (Zustand der trüben Schwellung der Elemente, sowie vergrösserter Umfang derselben), bald im Gegentheil verkleinert und blutarm (fettige Degeneration der Zellen, Uebergang in körnige Kügelchen und Resorption derselben. 
c) In dem Urin der Thiere, walche andauernd Silber gebraucht haben, wurde in vielen Fällen dit Anwesenheit von Eiweiss constatirt, dabei war die Marksubstanz der Niejen blutreicher als die Rindensubstanz.

d) Die Gallenblase fand man in der Mehrzahl der Fälle von einer starken Ansammlung von Galle ausgedehnt. Diesem Ueberfluss an Galle entsprechend enthictten, wie wir es oben angeführt, die Darmausleerungen eine bedeutende Beimischung von dieser Flüssigkeit, in welcher auf chemisuhem Wege das Vorbandensein von Silber constatirt worden ist (siehe die Anmerkung Beobachtung VII.).

e) Ausser auf die Leber und die Nieren dehnte das Silber seinen Einfluss auf das Muskelgewebe aus. In den Muskelfasern des Herzens wurden in einigen Versuchen Veränderungen beobachtet, welche den in den oben genannten Organen vorgegangenen Prozessen analog waren, die Muskelfasern waren in ihrem Umfange vergrössert, sie wurden trübe und von einer reichen Menge einer körnigen Masse bedeckt, welche bei Zusatz von Essigsäure verschwand; die Querstreifung der Muskelfasern war verwischt und nicht selten wurde eine Vergrösserung der Kerne des Sarkolema beobachtet; eine vollständig ausgesprochene fettige Degeneration der Muskelfasern des Herzens haben wir jedoch kein einziges Mal beobachten können. Aehnliche Veränderungen haben wir gleichfalls auch in den anderen Muskeln des Körpers gefunden.

f) Das Fettgewebe war in der Mehrzahl der Fälle atrophisch und das intermusculäre Zellgewebe oft schleimig degenerirt.

g) Eine allgemeine Blutstauung (Ueberfüllung aller" Venen des Körpers mit verflüssigtem, Gerinnsel enthaltendem Blute, Hypostase der Lungen, Ueberfüllung der ('efässe der Marksubstanz der Nieren) war die allgemeine Erscheinung, welche bei der Section aller durch acute oder chronische Einwirkung des Silbers getödteten Thiere beobachtet wurde. Nicht selten Transsudation in den beiden Pleurasäcken und im Pericardium als Folge dieser Staung.

h) In vielen der beobachteten Fälle fand man die Harnblase in Folge der Erkrankung des Rückenmarks ausgedehnt, was sich gewöhnlich einige Tage vor dem Tode der an chronischer Vergiftung zu Grunde gebenden Thiere einzustellen pflegte.

i) Der anhaltende Gebrauch des Silbers in progressiven Dosen bewirkt eine Gewichtsabnahme und stört sichtlich die Ernährung, indem er eine Verarmung an Blat und eine chlorolische Umände- 
rung desselben hervorruft. Dieser letztere Zustand trat am schnellsten bei der subcutanen Einführung der Silbersalze ein.

Die Ursache der allgemeinen venösen Stauung, welche sowohl bei der acuten, als auch bei der chronischen Einwirkung des Silbers beobachtet wurde, glauben wir in der Erkrankung des Herzens und des Respirationsapparates suchen zu müssen. In der. That witrde bei allen von uns bewirkten acuten Vergiftungen die Herzaction stets beeinträchtigt und die Respiration eine unregelmässige und frequente, woraus sich dann wiederum als natüliche Folge eine Blutstockung in den Lụngen, überhaupt Ueberfüllung in den Venen des ganzen Körpers herleiten. Solchen acuten Ersebeinungen der acuten Einwirkung des. Silbers entsprechend wurden bei der chronischen Wirkung des Metalls zugleich materielle Veränderungen in den Wandungen des Herzens gefunden (trübe Schwellung der Muskelfasern, Auftreten einer körnigen Masse und Vermehrung der Kerne des Sarkolemma), ein Zustand, welcher ohne Zweifel alterirend auf die functionelle Thätigkeit dieses Organes gewirkt haben muss.

Dies zugestanden haben wir, wie oben schon erwähnt, auch eine vollständige Begründung der anomalen Blutcirculation der allgemeinen venösen Ștase gefunden.

Anders verhält es sich mit der Erklärung für die Entstehung des so ausgesprochenen Magen- und Darmkatarrhs. Man könnte leicht versucht sein, ihn wiederum nur aus der allgemeinen venösen Blutstase herzuleiten, wie ja in der That dieser Zustand die häufigste Ursache des Katarihs ist. Wo bliebe dann aber die Quelle der materiellen Veränderungen in den Elementen der Leber und Niere, die wir besonders als trübe Schwellung und fettige Degeneration kennen gelernt haben? Vielleicht" der durch die Ablagerung des Silbers in die Gewebe erzengte chronische Reiz, wie uns Aehnliches die Experimente Stuart's in Bezug auf die Cauterisation von Froschmuskeln : mittelst Lapis infernalis andeuten (Schmidt's Jahrbücher der gesammten Medicin 1866. No. II)? Dass Derartiges hier nicht Statt hat, geht daraus hervor, dass einerseits auch die geringste Spur eines derartigen Reizes fehlt, andererseits das constante Vorhandensein der Argyrie die Möglichkeit einer solchen Annahme vollständig ausschliesst.

Es ist deshalb natïrlicher, diesen Prozess von den im Blute vor sich gegangenen Veränderungen -und von der Beeinträchtigung 
der Oxydation abzuleiten, - eine Erscheinung, die auch bei anderen dem Silber ähnlichen Metallea vorkommt. In der That wurde das Blut der mit Silber vergifteten Thiere, wie wir es oben nachgewiesen haben, lackfarben, indem die Blutkörperchen allmählich unter Abgabe ihres Hämoglobins an das Plasma ein blasses Aussehen bekamen. Dadurch musste der Oxydationsprozess und zwar gleichen Schrittes mit der Einwirkung des Silbers immer mehr und mehr darnieder sinken und demnächst der Stoffwechsel nothwendig erschwert und verlangsamt werden, was mit der Wahrnehmung in Betreff des allmählichen Sinkens der Temperatur, das wir bei allen Versuchen zu constatiren Gelegenheit hatten, vollkommen übereinstimmt.

Solche Erseheinungen sind es, bei welchen die Momente zur Entwickelung von passiven Prozessen und in Folge dessen zur Zerstörung der Gewebe sich darbieten.

Wenn wir daher auch keineswegs den unmittelbaren Einfluss des Silbers sowohl auf diè vegetative Function der Gewebe im Allgemeinen, als auch auf die chemische Zusammensetzung und den Zersetzungsprozess in denselben übersehen, so glauben wir nichtsdestoweniger dennoch annehmen zu dürfen, dass eine der wichtigsten Ursachen für.die Erscheinung der fettigen Degeneration in diesen Organen, wie sie auch bei Vergiftung mit Phosphor, Arsen, Antimon, Mangan etc. auftritt, die Beeinträchtigung des Oxydationsprozesses ist, der nun seinerseits wiederum von der gesunkenen Function der ihres Hằmoglobins verlustig 'gegaugenen Blutkörperchen abhängt.

Fast in allen obductionen der nach anhaltendem Gebrauch des Silbers zu Grunde gegangenen Thiere war die Gallenblase constant stark gedehnt und eine ausserordentliche Ansammlung von Galle in derselben vorgefunden, eine Erscheinung, die möglicherweise von dem bedeutenden Zufluss des Gallenfarbstoffes aus dem Blute, in Folge der continuirlichen Auflösung des Hämoglobins in Plasma und der anderweitigen Veränderungen des ersteren herzuleiten ist.

Was den Zustand des Marasmus anbetrifft, welchem die Kaninchen stets anheimfielen, so erklären wir denselben als durch die Einwirkung des Mittels auf das Blut der Thiere entstanden, wenn sich auch andererseits gegen die Annahme, dass die Abmagerung von der wegen des ausgesprochenen Magen- und Darmkatarrhs erschwerten Resorption der Nahrung herruhre, nichts sagen liesse. Möglich, dass hier beide Momente zugleich mitwirken. 